\title{
Estimating Population Norms for the Health-Related Quality of Life of Adults in Southern Jiangsu Province, China
}

wei Hu

Soochow University Medical College https://orcid.org/0000-0003-3526-5773

Liang Zhou

Liyang Center for Diseases Control and Prevention

Jiadong Chu

Soochow University

$\mathrm{Na}$ Sun

Soochow University

Shuting Xiong

Soochow University

Xuanli Chen

Soochow University

Siyuan Liu

Soochow University

yue ping Shen ( $\nabla$ shenyueping@suda.edu.cn )

Soochow University

Research

Keywords: EQ-5D-5L, health-related quality of life, population norms, Jiangsu

Posted Date: July 7th, 2021

DOI: https://doi.org/10.21203/rs.3.rs-672348/v1

License: @) (1) This work is licensed under a Creative Commons Attribution 4.0 International License. Read Full License 


\section{Abstract}

Purpose

Health-related quality of life (HRQoL) population norms have been published in China but only for urban populations. Moreover, China is large and diverse in culture and social development, and regional population norms may be more appropriate than national norms. The purpose of the study was to derive the HRQoL population norms for adults in southern Jiangsu Province and explored potential influencing factors.

Methods

The data were based on a cross-sectional survey conducted in Liyang City from March 2019 to July 2020. EQ-5D-5L utility scores based on Chinese value set and EQ-VAS scores were used to assess HRQoL. The Tobit regression model and generalized linear model were performed to identify the association among potential covariates and HRQoL.

Results

The means (95\% confidence interval) of the EQ-5D-5L utility scores and VAS scores were 0.981(0.980-0.983) and 83.6(83.2-83.9), respectively. Younger people were more likely to experience problems with anxiety or depression. Lower HRQoL was associated with elderly individuals, lower socioeconomic status, no spouse, lack of regular physical activities, smoking cessation, and chronic non-communicable diseases. Subjects who declared that they were afflicted by diseases presented significantly lower utility scores, ranging from $0.823(0.766-0.880)$ for memory-related diseases to 0.978 (0.967-0.989) for hepatic diseases.

\section{Conclusions}

Regional population norms of HRQoL are needed in the health economic study owing to the great socioeconomic differences across regions in China. The present study provides HRQoL population norms for adults in southern Jiangsu. These norm values could help policy makers better allocate limited health resources and prioritize service plans.

\section{Introduction}

In recent years, economic evaluation has been widely adopted to guide clinical practice and public health policy decisions(1). one of the most frequently reported benefit measurements in economic evaluations is quality adjusted life years, which combines quality of life and length of life into a single healthrelated quality of life (HRQoL) score(2). If a study does not have a control group and wants to evaluate the effect of its intervention, an estimate for HRQoL score norms in a population can serve as a reference group(2). Moreover, population norms enable researchers to compare the burden of disease with the health of the general population and to measure health inequalities (3). HRQoL population norms can also be treated as the key to determining whether the scores of a specific group or individual are above or below the average level for similar population(4). Therefore, assessing the HRQoL of the general population to construct population norms is becoming a necessity for the development of healthcare in each country.

HRQoL is a self-reported outcome that is increasingly used to monitor the health status of the general population. It is a multidimensional concept that reflects the physical, psychological, social and emotional well-being of the respondents(5). To date, there are many different instruments for measuring HRQoL, including the EuroQol five-dimension (EQ-5D), Health Utilities Index (HUI)(6), and the Short form 6-dimension (SF-6D)(7). The EQ-5D is one of the major selfreported instruments to evaluate HRQoL due to its simplicity, low respondent burden and high universal acceptance $(8,9)$. There are two versions of the EQ-5D, namely, the EQ-5D-3L and the EQ-5D-5L. In recent studies, the EQ-5D-5L has been widely used because it can reduce the ceiling effect (the proportion of respondents reporting "no problems" for all dimensions) detected in the EQ-5D-3L(10). This method has higher convergence validity and is more sensitive to slight health changes $(11,12)$. In the current study, the EQ-5D-5L value set based on the health preferences of the Chinese population was used to convert the health status in the EQ-5D into utility scores for subsequent HRQoL evaluation(13). In China, the research using the EQ-5D-5L to evaluate HRQoL is still quite limited $(14,15)$, so this study uses the EQ-5D-5L scale to evaluate the HRQoL of residents in southern Jiangsu.

In the field of public health, the population norm (average population score) of a region is often expressed as the EQ-5D-5L utility score, and the population norm is the benchmark for evaluating population health care and health equity. Although the EQ-5D-5L population norm has been reported in China's urban population(16), due to its small sample size (1,332 people were included in 5 regions), it may not be representative of all regions in China, let alone Jiangsu Province, which has a relatively developed economic level. Furthermore, China is a vast country, and the cultural and social development of each province is different. Thus, regional population norms may be more appropriate than national norms. The main purpose of this study is to derive the HRQoL population norms in the southern area of Jiangsu Province, China based on a large number of randomly sampled data from the Liyang Chronic Disease Risk Factor Monitoring Cohort Study (The Liyang Study) and the EQ-5D-5L China value set. Second, we examine the association between sociodemographic characteristics, health needs and HRQoL.

\section{Methods}

\section{Study Design and Data Collection}

The Liyang Study, is an ongoing, face-to-face, and cross-sectional observational study launched in March 2019. Liyang City is located in the south of Jiangsu Province, in the Yangtze River Delta area, a developed city in the economic zone of Shanghai. Its health level can reflect the basic situation of the population in the developed areas south of the Yangtze River in China, with a certain representativeness. The method of multi-stage stratified cluster random sampling was 
adopted to randomly select 17 townships or communities of Liyang City for investigation. We designed a standardized questionnaire including sociodemographic characteristics, behavioral lifestyle factors, health-related information, and the EQ-5D scale to collect data.

Trained local health workers were recruited to conduct a questionnaire survey on selected participants through face-to-face interviews in the nearest community hospital, and the interviews were recorded for subsequent quality control. The questionnaires were issued and retrieved on the same day, and missing or incorrect items were supplemented, proofread and logically corrected in a timely manner. The inclusion criteria were as follows: local permanent residents, age $\geq 18$ years old, complete sociodemographic information, and completion of the EQ-5D-5L scale. Before the study began, participants were informed about the purpose of the study, its health benefits and potential harms. Participants were asked to give written informed consent, and both researchers and respondents agreed to use the data only for scientific research purposes. This study was approved by the Ethics Review Committee of Soochow University and all respondents provided written informed consent.

\section{EQ-5D-5L}

The EQ-5D-5L scale for the determination of the population HRQoL consists of a five-dimensional health description system and a self-reported overall health score using the EuroQol Visual Analog Scale (EQ-VAS). The descriptive system comprises the dimensions of mobility (MO), self-care (SC), usual activities (UA), pain/discomfort (PD), and anxiety/depression (AD), and each dimension has five levels of response (from "no problems" to "extreme problems")(17). To better understand the distribution of health problems experienced by respondents, we converted each dimension into the dichotomous variables of "0"(no problems) and "1"(problems, slight/moderate/severe/extreme problems are collectively referred to as "problems"). The utility score is generated by applying the Chinese time trade-off model developed by Liu et al (18). The utility score ranges from - 0.391 for the worst (55555) to 1 for the best (11111) EQ-5D-5L health states. The EQ-VAS score is the self-reported overall health perception of the respondents. It records the respondent's self-rated health on a vertical scale from 0 (the worst health) to 100 (the best health), where the respondents picture their health status on the interview day. Respondents with higher utility scores or VAS scores are healthier than those with lower scores.

\section{Covariates}

\section{Sociodemographic factors}

Sociodemographic factors including sex, age (18-30, 31-40, 41-50, 51-60, 61-70, and 70+ years), residence(urban/rural), education level (primary school and below, junior middle school, high school or similar and junior college and above), marital status(married, unmarried/divorced/widowed), annual household income ( $<50,000$ yuan, 50,000-99,999 yuan, 10,0000-14,9999, and $\geq 15,0000$ yuan, RMB), employment status(employed/full-time/part-time,

unemployment/retirement/housework/student), and body mass index(BMI, low BMI, $<18.5 \mathrm{~kg} / \mathrm{m}^{2}$; normal BMI, between 18.5 and $24.0 \mathrm{~kg} / \mathrm{m}^{2}$; overweight BMI, between 24.0 and $28.0 \mathrm{~kg} / \mathrm{m}^{2}$; and obese $\mathrm{BMl}, \geq 28.0 \mathrm{~kg} / \mathrm{m}^{2}$, following recommendations from the Working Groupon Obesity in China(19)).

\section{Behavioral lifestyle factors}

Behavioral variables included: smoking, defined as at least one cigarette per day for 6 months (never, current, or former); alcohol consumption, defined as at least once a month (never, current); and regular physical activity, defined as moderately intense activity lasting more than 10 minutes at least once a week (yes, no)(20).

\section{Health-related factors}

The participants were also asked whether they had a health problem affecting HRQoL (e.g., mental illness, memory related illness), and their general health needs. Health needs were measured by chronic non-communicable diseases (NCDs), which included hypertension, diabetes, dyslipidaemia, stroke, coronary heart disease (CHD), asthma, chronic obstructive pulmonary disease (COPD) and cancer. NCDs were defined as a condition diagnosed by a doctor from a secondary or above medical institution, for which either the symptoms persisted or relevant medical treatment continued over the past year (21). Participants were classified as having no NCDs, or one, two or more NCDs.

\section{Statistical Analysis}

Frequencies and percentages were used for categorical variables, and all covariates including age were entered into the model as categorical variables. Means and $95 \%$ confidence intervals [Cls] were calculated for the continuous variables (including the EQ-5D-5L utility score and EQ-VAS score). The differences in utility scores and VAS scores between different subgroups were tested by employing Wilcoxon or Kruskal-Wallis tests. The Wilcoxon test was also used to describe differences in utility scores and EQ-VAS scores between men and women for age categories, education levels, income levels, and BMI categories. Mann-Whitney test was used to examine the difference in the mean utility score and VAS score in different dimensions of the EQ-5D-5L scale. In addition, the chi-square test was used to compare the incidence of problems for each EQ-5D dimension by gender and age.

The relationships between all covariates and EQ-VAS scores were explored using a generalized linear model (GLM) with a Poisson distribution and a log link based on the modified Park test (22). Since the distribution of the EQ-5D utility scores was skewed and censored at 1, we used the multivariate Tobit regression model to evaluate the relationship between EQ-5D utility score and potential influencing factors(23). All data analysis was performed in SAS version 9.4(SAS Institute Inc., Cary, NC, USA) and STATA version 15.0. A P value below 0.05 was considered statistically significant.

\section{Results}

\section{Sample Characteristics}


A total of 10,200 individuals aged 18 and above participated in the study, and 144 respondents did not complete the EQ-5D-5L questionnaire, leaving 10,056(response rate: $98.6 \%$ ) respondents who enrolled in this study. More than half (53.8\%) completed the EQ-5D-5L scale, but 4976 did not complete the EQVAS. The sociodemographic characteristics and health needs of the respondents are summarized in Table 1.

\section{EQ-5D-5L utility scores and EQ-VAS scores}

The respondents possessed a mean EQ-5D-5L utility score of 0.981(0.980-0.983) (95\%Cl) and a mean EQ-VAS score of 83.6(83.2-83.9). Subjects with lower utility scores were those who were elderly, were women, lived in rural areas, were ex-smokers, were unmarried/divorced/widowed, had no paid employment, had high BMI, had a lower education level or lower annual household income, lacked regular physical activity and suffered from one or more NCDs. Similar results were observed for EQ-VAS scores except for sex and drinking (All $P<0.05$, Table 1).

The EQ-5D-5L utility score ranged from -0.251 to 1 , which was left-skewed with the dominant value at 1.00 (i.e., "Full health"). Only 7 subjects had negative utility scores. Of the subjects, $85.6 \%$ had the highest utility score (EQ-5D-5L utility score $=1,11111$ health state). Similarly, the EQ-VAS score was ranged from 0 to 100 , which was also left-skewed with the major clustering from 80 to 100 (i.e., "the best health you can imagine"). Only $23.6 \%$ of subjects had an EQ-VAS score of 90 and above. The other most common health states were $11121,11112,11122$, and 22221 in the proportions of $6.4 \%, 1.3 \%, 1.2 \%$, and $0.2 \%$, respectively.

For men, the condition that had the greatest impact on quality of life was the memory-related diseases, followed by stroke and mental diseases, while for women, stroke was the most significant, followed by memory-related diseases and asthma. In terms of EQ-VAS scores, slightly different from the utility scores, men with COPD had the lowest VAS scores, while women were still most affected by stroke (Table 2).

The EQ-5D-5L utility score was presented by age, education level, income, and BMI and was divided according to sex. In general, utility scores are higher in men than in women, with especially significant differences in the 41-50 and 61 + age groups, and the scores for both sexes decline with age. Education level, income and BMI also appeared to influence utility scores in which people with low education, low income and a BMI of 24.0 and above generally scored lower. In addition, we found that men and women had different utility scores in household annual income and BMI (All $P<0.05$, Table 3).

Utility scores and VAS scores varied significantly according to whether the respondents reported any problems in each dimension. Overall, regarding the EQVAS, people without problems had 6 scores points higher than people with at least one problem. Moreover, regarding the EQ-5D-5L utility score, respondents reporting one problem had utility score 0.13 points lower than respondents reporting no problems (All $P<0.001$, Table 4).

\section{Health problems reported by respondents.}

The highest proportion of all respondents reported problems in PD (12\%), followed by AD (5\%), while the lowest percentage reported problems in SC ( $2 \%)$. The percentage of reported problems with MO, UA, SC, and PD increased with age in the total, male, and female samples, respectively. In contrast, younger age groups (age 18-30 and age 31-40) reported more health restrictions with AD (All $P<0.001$, Table 5).

\section{Potential influencing factors of HRQoL}

Advanced age, living in rural regions, no spouse, quitting smoking, lack of regular physical activity, and suffering from NCDs had a statistically negative impact on HRQoL. In contrast, higher education level, higher annual income, and paid employment exerted a positive effect on HRQoL, as measured by the utility score. The results for the EQ-VAS score were similar, although not statistically significant for physical activity. Regarding EQ-VAS, women and drinkers seemed to have lower scores; however, a statistical association between sex, drinking and utility scores was not found (All $P<0.05$, Table 6$)$.

\section{Discussion}

Our study identified some sociodemographic factors influencing HRQoL: old age, lower education levels, lower income levels, residence in rural areas, no spouse, no paid work, lack of regular physical activities and ex-smokers. In addition, NCDs had a significant impact on HRQoL. To our knowledge, this is the first study to estimate the HRQoL population norms for residents in southern Jiangsu Province of China using the EQ-5D-5L questionnaire based on a randomly selected large sample data. The population norms in the study can be used as reference data to compare profiles for patients with specific conditions with data for the average person in the general population in a similar age and gender group(3) and provide evidence for evaluating the effectiveness of future public health interventions. To date, studies have determined the EQ-5D-5L population criteria of other provinces in China, while few studies have included Jiangsu Province, and those that do include Jiangsu adopt very small and unrepresentative sample sizes (16, 24, 25). In addition, previous studies have shown that the EQ-5D-5L scale can effectively reduce the ceiling effect on the $3 \mathrm{~L}$ scale $(26,27)$, so the $5 \mathrm{~L}$ scale is used in this study.

Generally, the mean utility score is 0.98 , which is similar to that of the USA (0.97)(28), slightly higher than that of the urban population of China (0.96)(16), and significantly higher than those of Poland (0.89)(29), and Portugal (0.89)(26). The mean VAS score (83.57) is higher than the national average (80.12) of China (21). However, direct comparison of utility scores between different countries or regions are not recommended because regions have different sociodemographic compositions and health policies, which may influence respondents' choice of different dimensions of the EQ-5D scale(30). The findings showed that the respondents experienced greater problems with PD and AD and fewer problems with SC and UA, which is consistent with the EQ-5D-5L population studies in other countries $(29,31,32)$. Approximately $12 \%$ of participants reported PD, similar to the Chinese average (21)but well below the averages reported by Poland, the United States, and Greece (33-35). Interestingly, AD was more common in younger adults (40 years and younger), as has been reported elsewhere $(16,24)$. One possible explanation is that the younger generation feels more psychological pressure than the older generation because of the fast pace of life in developed cities (16). 
Ageing presents a great challenge to the world, in both developed and developing nations(36). HRQoL tended to deteriorate with age, as observed in other studies $(21,29,31,32,37,38)$. As expected, elderly people were more likely to experience problems in all EQ-5D-5L dimensions. The multivariate models established in our study showed that NCDs were a significant predictor of HRQoL. NCDs have become a major cause of death worldwide (39). People with NCDs had lower utility scores and VAS scores resulting in a worse HRQoL. This is consistent with relevant research results $(25,40)$.

Previous studies have shown that HRQoL inequality exists in different socioeconomic regions in China, such as Hong Kong (utility score 0.920 ) (24) and the urban population in mainland China $(0.957)(16,22)$. Our study also confirmed this phenomenon: people with higher socioeconomic status (higher income, better education, and paid employment) had better HRQoL, which was consistent with previous studies $(21,41,42)$. An individual's socioeconomic status is often represented by education, income and employment $(21,43)$. Educational attainment is the most important of the three factors that constitute an individual's socioeconomic status because it is fairly stable throughout the life course of a person. Furthermore, it can shape one's career and expected income potential. Through this mechanism, its indirect link to health is stronger than its direct impact (44).

In addition, those without a spouse tended to have a lower HRQoL. These people may experience social isolation and financial stress, which could lower their well-being (45). People who often engaged in physical activity had relatively better HRQoL. Regularly undertaking both aerobic and muscle strengthening activities, such as walking and cycling, have significant benefits for health (46). Our study also found an interesting phenomenon: ex-smokers had significantly lower utility scores. This is similar to the findings of Zhuo ru Liang et al., who suggest that there may be a "healthy smoker" phenomenon, where smokers believe that smoking relives pain and stress, while ex-smokers are likely forced to quit smoking due to a disease (47).

One advantage of our study is that it has a sufficient sample size (10056) and a high respondent response rate (98.59\%) and is generally representative of the population. In addition, Tobit regression and GLM were used to replace the traditional linear regression model in the multivariate analysis, which was in line with the distribution characteristics of health utility value and EQ-VAS score, making the analysis results more following the actual situation. Finally, this study provides utility scores and VAS scores for various diseases, which is rare in related studies (48) and could be useful for health policymakers when prioritizing resource allocation.

There are some weaknesses worth mentioning in the present study. First, as a cross-sectional design, the correlation between HRQoL and potential variables cannot be interpreted as causal. Moreover, approximately $50 \%$ of respondents had missing values for the EQ-VAS. Further analysis indicates that the distribution of all sociodemographic variables for the sample with missing EQ-VAS score values was generally consistent with that for the sample with complete EQ-VAS scores.

\section{Conclusions}

This is the first study to provide HRQoL norms using the EQ-5D-5L scale for adults in southern Jiangsu, China and explore its potential influencing factors. These norm values can be used to rationalize the allocation of limited health resources and to evaluate and compare the effects of different medical interventions in health care. However, the study found evident socioeconomic inequalities in HRQoL. Therefore, health inequalities deserve the attention of policy makers, and targeted research on each HRQoL domain can promote further understanding of underlying characteristics of inequalities and identify effective strategies to address them to promote greater equity.

\section{Declarations}

\section{Author contributions}

Study design: Wei Hu, Liang Zhou, Jiadong Chu, Data collection and management: Wei Hu, Na Sun, Shuting Xiong, Xuanli Chen. Data analyses: Wei Hu, Siyuan Liu, and Yueping Shen. All authors were involved in the manuscript preparation and all authors read and approved the final manuscript.

\section{Funding}

This work was supported by the National Natural Science Foundation of China (project number 81973143) and the Priority Academic Program Development of Jiangsu Higher Education Institutions (PAPD). All of the authors have participated actively in this study, and agree to the content of the manuscript and their being listed as an author on the paper.

\section{Ethical approval}

This study was approved by the Ethics Review Committee of Soochow University and all respondents provided written informed consent.

\section{Consent to participate}

All respondents provided written informed consent prior to the interview.

\section{Competing Interests}

The authors have declared that no competing interest exists.

\section{References}


1. Ravens-Sieberer U. Measuring and monitoring quality-of-life in population surveys: still a challenge for public health research. Sozial- und Praventivmedizin. 2002; 47: 203-4.

2. Poder TG, Carrier N, Kouakou CRC. Quebec Health-Related Quality-of-Life Population Norms Using the EQ-5D-5L: Decomposition by Sociodemographic Data and Health Problems. Value Health. 2020; 23: 251-59.

3. Hołownia-Voloskova M, Tarbastaev A, Golicki D. Population norms of health-related quality of life in Moscow, Russia: the EQ-5D-5L-based survey. Qual Life Res. 2021; 30: 831-40.

4. Hopman WM, Towheed T, Anastassiades T, et al. Canadian normative data for the SF-36 health survey. Canadian Multicentre Osteoporosis Study Research Group. CMAJ : Canadian Medical Association journal = journal de l'Association medicale canadienne. 2000; 163: $265-71$.

5. Carr AJ, Gibson B, Robinson PG. Measuring quality of life: Is quality of life determined by expectations or experience? BMJ (Clinical research ed). 2001; 322: $1240-3$.

6. Feeny D, Furlong W, Boyle M, et al. Multi-attribute health status classification systems. Health Utilities Index. Pharmacoeconomics. 1995; 7 : $490-502$.

7. Brazier J, Roberts J, Deverill M. The estimation of a preference-based measure of health from the SF-36. Journal of health economics. $2002 ; 21: 271-92$.

8. Chen PC, Kuo RN, Lai CK, et al. The relationship between smoking status and health-related quality of life among smokers who participated in a 1-year smoking cessation programme in Taiwan: a cohort study using the EQ-5D. Bmj Open. 2015; 5: e007249.

9. Cunillera O, Tresserras R, Rajmil L, et al. Discriminative capacity of the EQ-5D, SF-6D, and SF-12 as measures of health status in population health survey. Qual Life Res. 2010; 19: 853-64.

10. Devlin NJ, Brooks R. EQ-5D and the EuroQol Group: Past, Present and Future. Appl Health Econ Health Policy. $2017 ; 15: 127-37$.

11. Feng $\mathrm{Y}$, Devlin N, Herdman M. Assessing the health of the general population in England: how do the three- and five-level versions of EQ-5D compare? Health Qual Life Outcomes. 2015; 13: 171.

12. Nguyen LH, Tran BX, Hoang Le QN, et al. Quality of life profile of general Vietnamese population using EQ-5D-5L. Health Qual Life Outcomes. 2017; 15: 199.

13. Luo N, Liu G, Li M, et al. Estimating an EQ-5D-5L Value Set for China. Value Health. 2017; 20: 662-69.

14. Xu RH, Cheung AWL, Wong EL. Examining the health-related quality of life using EQ-5D-5L in patients with four kinds of chronic diseases from specialist outpatient clinics in Hong Kong SAR, China. Patient Prefer Adherence. 2017; 11: 1565-72.

15. Liu L, Li S, Wang M, et al. Comparison of EQ-5D-5L health state utilities using four country-specific tariffs on a breast cancer patient sample in mainland China. Patient Prefer Adherence. 2017; 11: 1049-56.

16. Yang Z, Busschbach J, Liu G, et al. EQ-5D-5L norms for the urban Chinese population in China. Health Qual Life Outcomes. 2018; 16: 210.

17. Luo N, Li M, Liu GG, et al. Developing the Chinese version of the new 5-level EQ-5D descriptive system: the response scaling approach. Qual Life Res. 2013; $22: 885-90$.

18. Liu GG, Wu H, Li M, et al. Chinese time trade-off values for EQ-5D health states. Value Health. 2014; 17: 597-604.

19. Jia W. Obesity in China: its characteristics, diagnostic criteria, and implications. Frontiers of medicine. 2015; 9: 129-33.

20. Tierney M, Fraser A, Kennedy N. Criterion validity of the International Physical Activity Questionnaire Short Form (IPAQ-SF) for use in patients with rheumatoid arthritis: comparison with the SenseWear Armband. Physiotherapy. 2015; 101: 193-7.

21. Sun S, Chen J, Johannesson M, et al. Population health status in China: EQ-5D results, by age, sex and socio-economic status, from the National Health Services Survey 2008. Qual Life Res. 2011; 20: 309-20.

22. Li H, Wei X, Ma A, et al. Inequalities in health status among rural residents: EQ-5D findings from household survey China. International journal for equity in health. 2014; 13: 41.

23. Austin PC, Escobar M, Kopec JA. The use of the Tobit model for analyzing measures of health status. Qual Life Res. 2000; 9: 901-10.

24. Wong EL, Cheung AW, Wong AY, et al. Normative Profile of Health-Related Quality of Life for Hong Kong General Population Using Preference-Based Instrument EQ-5D-5L. Value Health. 2019; 22: 916-24.

25. Huang W, Yu H, Liu C, et al. Assessing Health-Related Quality of Life of Chinese Adults in Heilongjiang Using EQ-5D-3L. International journal of environmental research and public health. 2017; 14. 
26. Ferreira LN, Ferreira PL, Ribeiro FP, et al. Comparing the performance of the EQ-5D-3L and the EQ-5D-5L in young Portuguese adults. Health Qual Life Outcomes. 2016; 14: 89.

27. Shiroiwa T, Ikeda S, Noto S, et al. Comparison of Value Set Based on DCE and/or TTO Data: Scoring for EQ-5D-5L Health States in Japan. Value Health. 2016; 19: 648-54.

28. Augustovski F, Rey-Ares L, Irazola V, et al. An EQ-5D-5L value set based on Uruguayan population preferences. Qual Life Res. 2016; 25 : 323-33.

29. Golicki D, Niewada M. EQ-5D-5L Polish population norms. Archives of medical science : AMS. 2017; 13: 191-200.

30. In: Szende A, Janssen B, Cabases J, eds., Self-Reported Population Health: An International Perspective based on EQ-5D. Dordrecht (NL): Springer

Copyright 2014, The Editor(s) (if applicable) and the Author(s). 2014.

31. McCaffrey N, Kaambwa B, Currow DC, et al. Health-related quality of life measured using the EQ-5D-5L: South Australian population norms. Health Qual Life Outcomes. 2016; 14: 133.

32. Hinz A, Kohlmann T, Stöbel-Richter Y, et al. The quality of life questionnaire EQ-5D-5L: psychometric properties and normative values for the general German population. Qual Life Res. 2014; 23: 443-7.

33. Golicki D, Niewada M, Jakubczyk M, et al. Self-assessed health status in Poland: EQ-5D findings from the Polish valuation study. Polskie Archiwum Medycyny Wewnetrznej. 2010; 120: 276-81.

34. Luo N, Chew LH, Fong KY, et al. Validity and reliability of the EQ-5D self-report questionnaire in Chinese-speaking patients with rheumatic diseases in Singapore. Annals of the Academy of Medicine, Singapore. 2003; 32: 685-90.

35. Kontodimopoulos N, Pappa E, Niakas D, et al. Validity of the EuroQoL (EQ-5D) instrument in a Greek general population. Value Health. 2008 ; 11: 1162-9.

36. Zhang NJ, Guo M, Zheng X. China: awakening giant developing solutions to population aging. The Gerontologist. 2012; 52: 589-96.

37. Abdin E, Subramaniam M, Vaingankar JA, et al. Measuring health-related quality of life among adults in Singapore: population norms for the EQ-5D. Qual Life Res. 2013; 22: 2983-91.

38. Shiroiwa T, Fukuda T, Ikeda S, et al. Japanese population norms for preference-based measures: EQ-5D-3L, EQ-5D-5L, and SF-6D. Qual Life Res. 2016; 25: 707-19.

39. Mendis S, Davis S, Norrving B. Organizational update: the world health organization global status report on noncommunicable diseases 2014; one more landmark step in the combat against stroke and vascular disease. Stroke. 2015; 46: e121-2.

40. Rezaei S, Hajizadeh M, Kazemi A, et al. Determinants of health-related quality of life in Iranian adults: evidence from a cross-sectional study. Epidemiology and health. 2017; 39: e2017038.

41. Kularatna S, Whitty JA, Johnson NW, et al. EQ-5D-3L derived population norms for health related quality of life in Sri Lanka. Plos One. 2014 ; 9: e108434.

42. Health-related quality of life and psychological distress among cancer survivors in Southeast Asia: results from a longitudinal study in eight low- and middle-income countries. BMC medicine. 2017; 15: 10.

43. Grundy E, Holt G. The socioeconomic status of older adults: how should we measure it in studies of health inequalities? Journal of epidemiology and community health. 2001; 55: 895-904.

44. Singh-Manoux A, Clarke P, Marmot M. Multiple measures of socio-economic position and psychosocial health: proximal and distal measures. International journal of epidemiology. 2002; 31: 1192-9; discussion 99-200.

45. Wickrama KA, Lorenz FO, Conger RD, et al. Changes in family financial circumstances and the physical health of married and recently divorced mothers. Social science \& medicine (1982). 2006; 63: 123-36.

46. Bull FC, Al-Ansari SS, Biddle S, et al. World Health Organization 2020 guidelines on physical activity and sedentary behaviour. British journal of sports medicine. 2020; 54: 1451-62.

47. Choi D, Ota S, Watanuki S. Does cigarette smoking relieve stress? Evidence from the event-related potential (ERP). Int J Psychophysiol. 2015; 98: 470-6.

48. van den Berg B. Sf-6d population norms. Health Econ. 2012; 21: 1508-12.

\section{Tables}

Table 1. EQ-5D-5L utility scores and EQ-VAS scores according to sample characteristics. 


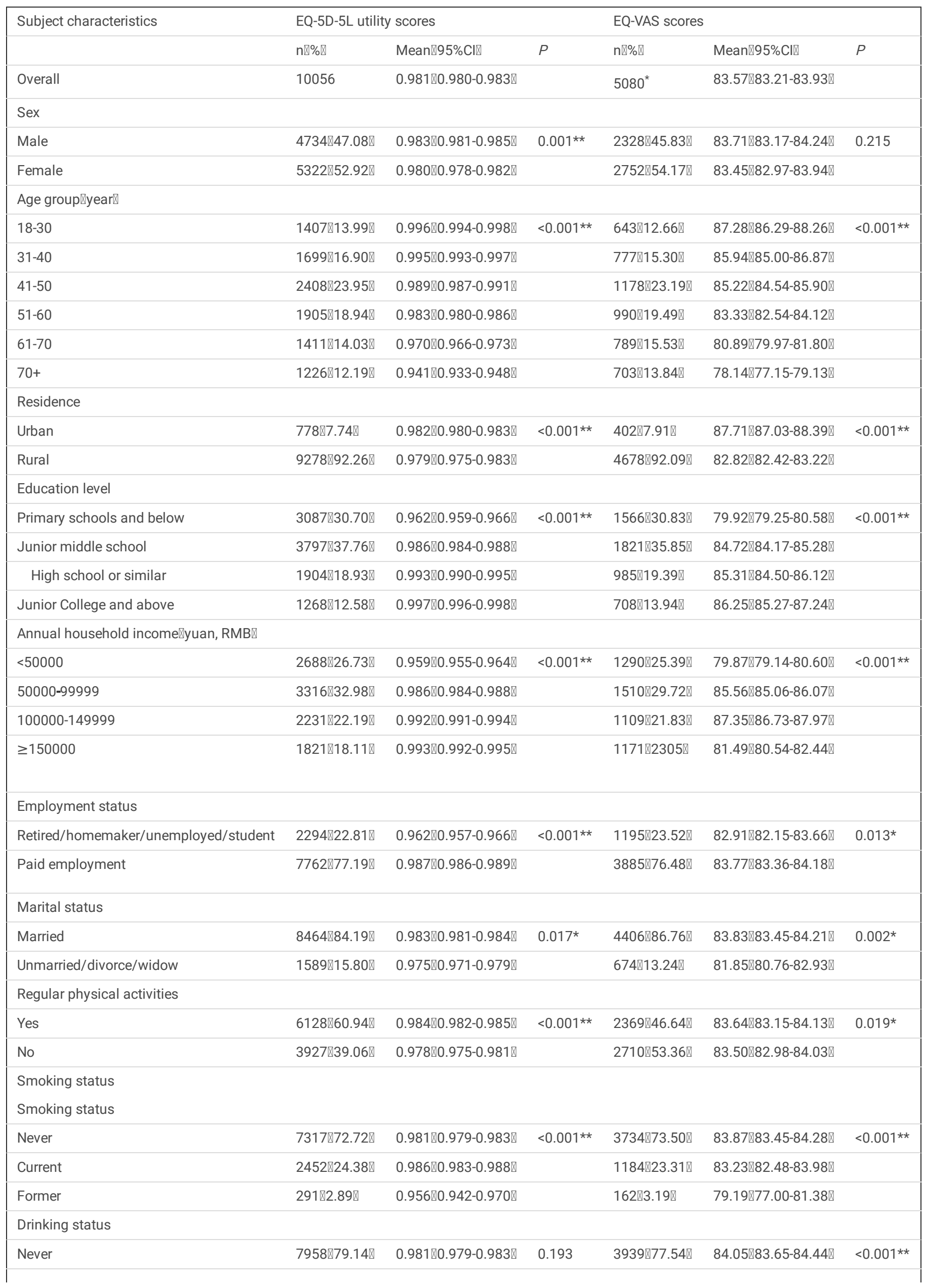

Page 8/15 


\begin{tabular}{|c|c|c|c|c|c|c|}
\hline Current & 2098ه20.86】 & $0.983 \rrbracket 0.981-0.986 \rrbracket$ & & $1141 \rrbracket 22.46 \rrbracket$ & 81.92ه81.11-82.74】 & \\
\hline \multicolumn{7}{|l|}{$\mathrm{BM} \varangle \mathrm{kg} / \mathrm{m}^{2} \square$} \\
\hline$\leq 23.9$ & $5641 ه 56.10 \bigotimes$ & $0.983 \rrbracket 0.982-0.985 \rrbracket$ & $<0.001 * \star$ & $2873 \llbracket 56.56 \rrbracket$ & $84.09 \llbracket 83.62-84.57 \rrbracket$ & $<0.001$ ** \\
\hline 24.0 to 27.9 & $3440 \rrbracket 34.21 \rrbracket$ & $0.980 \rrbracket 0.977-0.982 \rrbracket$ & & 1722ه33.90区 & $83.09 \llbracket 82.46-83.72 \rrbracket$ & \\
\hline$\geq 28.0$ & $975 \llbracket 9.70 \rrbracket$ & $0.975 \rrbracket 0.970-0.980 \rrbracket$ & & $485 \llbracket 9.55 \rrbracket$ & 82.16ه81.01-83.31凹 & \\
\hline 0 & 7638ه75.95】 & $0.989 \llbracket 0.988-0.990 \rrbracket$ & $<0.001 * \star$ & $3806 \llbracket 74.92 \rrbracket$ & $84.64 \llbracket 84.23-85.06 \rrbracket$ & $<0.001$ ** \\
\hline 1 & 1738ه17.28ه & $0.972 \varangle 0.968-0.976 \rrbracket$ & & $927 \rrbracket 18.25 \rrbracket$ & 81.23凶80.42-82.04ه & \\
\hline$\geq 2$ & $680 \rrbracket 6.76 \rrbracket$ & $0.922 \varangle 0.910-0.935 \rrbracket$ & & $347 \rrbracket 6.83 \rrbracket$ & $77.60 \otimes 76.10-79.11 \rrbracket$ & \\
\hline
\end{tabular}

** $P<0.001 ; * P<0.05$; The sample size of EQ-VAS was missing 4976; Cl, confidence interval; BMI, Body mass index; NCDs, chronic non-communicable diseases; Paid employment, whether employed, full-time or part-time.

Table 2. EQ-5D-5L utility scores and EQ-VAS scores for self-reported diseases with influencing HRQoL in men, women, and the total sample, respectively. 


\begin{tabular}{|c|c|c|c|c|c|c|c|}
\hline \multirow[t]{2}{*}{ Diseases } & \multicolumn{2}{|l|}{ Total } & \multicolumn{2}{|l|}{ Men } & \multicolumn{2}{|c|}{ Women } & \multirow[t]{2}{*}{$P$} \\
\hline & $\mathrm{N}$ & Mean $₫ 95 \% \mathrm{Cl} \rrbracket$ & $\mathrm{n}$ & Mean $\varangle 95 \% \mathrm{Cl} \rrbracket$ & $\mathrm{n}$ & Mean $\nabla 95 \% \mathrm{Cl} \rrbracket$ & \\
\hline \multicolumn{8}{|l|}{ EQ-5D-5L utility scores } \\
\hline No self-reported diseases & 6858 & 0.994『0.993-0.994囚 & 3205 & 0.994『0.993-0.995》 & 3653 & 0.993囚0.992-0.994区 & $0.046^{*}$ \\
\hline Hypertension & 1815 & $0.959 \rrbracket 0.953-0.964 \rrbracket$ & 887 & $0.966 \rrbracket 0.959-0.973 \rrbracket$ & 928 & $0.952 \varangle 0.944-0.959 \rrbracket$ & $<0.001^{\star *}$ \\
\hline Diabetes mellitus & 499 & $0.951 \llbracket 0.940-0.961 \rrbracket$ & 209 & $0.963 \rrbracket 0.949-0.977 \rrbracket$ & 290 & $0.941 \rrbracket 0.926-0.957 \rrbracket$ & 0.070 \\
\hline Dyslipidemia & 325 & $0.947 \rrbracket 0.934-0.960 \rrbracket$ & 148 & $0.965 \rrbracket 0.953-0.977 \rrbracket$ & 177 & $0.932 \varangle 0.911-0.952 \rrbracket$ & $0.014^{\star}$ \\
\hline Stroke & 185 & $0.854 \llbracket 0.819-0.888 \rrbracket$ & 91 & $0.868 \rrbracket 0.818-0.918 \rrbracket$ & 94 & $0.839 \llbracket 0.791-0.887 \rrbracket$ & $0.038^{*}$ \\
\hline $\mathrm{CHD}$ & 173 & $0.924 \llbracket 0.905-0.944 \rrbracket$ & 80 & $0.934 \llbracket 0.906-0.962 \rrbracket$ & 93 & $0.916 \rrbracket 0.888-0.943 \rrbracket$ & 0.173 \\
\hline COPD & 114 & $0.923 \llbracket 0.894-0.952 \rrbracket$ & 65 & $0.940 \rrbracket 0.902-0.977 \rrbracket$ & 49 & $0.901 \rrbracket 0.854-0.948 \rrbracket$ & 0.219 \\
\hline Asthma & 77 & $0.890 \rrbracket 0.841-0.939 \rrbracket$ & 41 & $0.916 \rrbracket 0.854-0.978 \rrbracket$ & 36 & $0.861 \rrbracket 0.780-0.941 \rrbracket$ & 0.071 \\
\hline Cancer & 110 & $0.959 \llbracket 0.938-0.980 \rrbracket$ & 49 & $0.979 \rrbracket 0.967-0.990 \rrbracket$ & 61 & $0.943 \rrbracket 0.907-0.980 \rrbracket$ & 0.331 \\
\hline Other respiratory diseases & 231 & $0.935 \rrbracket 0.918-0.952 \rrbracket$ & 135 & $0.941 \rrbracket 0.918-0.964 \rrbracket$ & 96 & $0.926 \rrbracket 0.900-0.952 \rrbracket$ & 0.202 \\
\hline Hepatic diseases & 63 & $0.978 \rrbracket 0.967-0.989 \rrbracket$ & 38 & $0.982 \varangle 0.969-0.996 \rrbracket$ & 25 & $0.972 \varangle 0.952-0.992 \rrbracket$ & 0.275 \\
\hline Cardiac diseases & 222 & $0.917 \rrbracket 0.898-0.936 \rrbracket$ & 104 & $0.927 \rrbracket 0.901-0.954 \rrbracket$ & 118 & $0.909 \varangle 0.881-0.936 \rrbracket$ & 0.196 \\
\hline Kidney diseases & 66 & $0.942 \rrbracket 0.912-0.973 \rrbracket$ & 31 & $0.955 \rrbracket 0.929-0.981 \rrbracket$ & 35 & $0.931 \rrbracket 0.877-0.986 \rrbracket$ & 0.903 \\
\hline Digestive system diseases & 791 & $0.946 \rrbracket 0.938-0.954 \rrbracket$ & 349 & $0.947 \rrbracket 0.935-0.959 \rrbracket$ & 442 & $0.945 \rrbracket 0.935-0.956 \rrbracket$ & 0.942 \\
\hline Mental diseases & 116 & $0.880 \rrbracket 0.840-0.919 \rrbracket$ & 53 & $0.872 \varangle 0.798-0.947 \rrbracket$ & 63 & $0.886 \rrbracket 0.844-0.927 \rrbracket$ & 0.311 \\
\hline Memory related diseases & 92 & $0.823 \llbracket 0.766-0.880 \rrbracket$ & 43 & $0.795 \rrbracket 0.694-0.896 \rrbracket$ & 49 & $0.847 \rrbracket 0.783-0.911 \rrbracket$ & 0.833 \\
\hline Arthritis & 530 & $0.921 ه 0.910-0.933 \rrbracket$ & 209 & $0.936 \rrbracket 0.921-0.952 \rrbracket$ & 321 & $0.912 \rrbracket 0.896-0.927 \rrbracket$ & 0.046 \\
\hline \multicolumn{8}{|l|}{ EQ-VAS scores } \\
\hline No self-reported diseases & 3433 & $85.10 \rrbracket 84.67-85.52 \rrbracket$ & 1557 & 85.27ه84.64-85.91》 & 1876 & $84.95 \rrbracket 84.38-85.53 \rrbracket$ & 0.214 \\
\hline Hypertension & 956 & $80.22 \llbracket 79.38-81.06 \rrbracket$ & 454 & $80.69 \rrbracket 79.47-81.90 \rrbracket$ & 502 & 79.80ه78.63-80.96》 & 0.239 \\
\hline Diabetes mellitus & 264 & $78.95 \llbracket 77.29-80.61 \rrbracket$ & 111 & 77.71ه74.97-80.45囚 & 153 & 79.85囚77.77-81.93囚 & 0.411 \\
\hline Dyslipidemia & 201 & 81.11ه79.23-82.99ه & 81 & $80.58 \bowtie 77.71-83.45 \rrbracket$ & 120 & 81.47囚78.96-83.98】 & 0.448 \\
\hline Stroke & 81 & 73.17ه69.16-77.19凹 & 37 & $74.11 \llbracket 69.07-79.15 \rrbracket$ & 44 & 72.39ه66.15-78.62》 & 0.970 \\
\hline $\mathrm{CHD}$ & 95 & $75.72 \otimes 73.22-78.21 \rrbracket$ & 49 & 73.94ه70.32-77.56冈 & 46 & 77.61ه74.13-81.09ه & 0.178 \\
\hline COPD & 43 & $73.63 \llbracket 68.61-78.65 \rrbracket$ & 27 & $71.78 \llbracket 65.07-78.49 \rrbracket$ & 16 & $76.75 \llbracket 68.66-84.84 \rrbracket$ & 0.389 \\
\hline Asthma & 30 & $75.73 \llbracket 67.95-83.52 \rrbracket$ & 15 & $76.80 \rrbracket 67.04-86.56 \rrbracket$ & 15 & 74.67囚61.25-88.09囚 & 0.983 \\
\hline Cancer & 51 & $79.10 \otimes 75.72-82.48 \rrbracket$ & 17 & $78.35 \bigotimes 71.46-85.24 \rrbracket$ & 34 & 79.47囚75.47-83.47囚 & 0.879 \\
\hline Other respiratory diseases & 123 & $76.46 \otimes 73.68-79.23 \rrbracket$ & 68 & 76.37ه72.90-79.83囚 & 55 & 76.56ه71.94-81.18ه & 0.672 \\
\hline Hepatic diseases & 39 & $84.56 \bowtie 81.07-88.05 \rrbracket$ & 20 & $87.25 \llbracket 83.35-91.15 \rrbracket$ & 19 & 81.74囚75.73-87.74囚 & 0.166 \\
\hline Cardiac diseases & 125 & $78.27 ه 76.00-80.55 \rrbracket$ & 64 & $77.02 \varangle 73.84-80.19 \rrbracket$ & 61 & 79.59ه76.27-82.91区 & 0.310 \\
\hline Kidney diseases & 40 & 88.33®85.63-91.02凹 & 21 & $91.00 \rrbracket 87.92-94.08 \rrbracket$ & 19 & $85.37 \rrbracket 80.92-89.82 \rrbracket$ & $0.048^{*}$ \\
\hline Digestive system diseases & 376 & 79.62囚78.38-80.87ه & 175 & $80.12 \bigotimes 78.25-81.99 \rrbracket$ & 201 & 79.19ه77.51-80.87ه & 0.295 \\
\hline Mental diseases & 40 & $78.43 \llbracket 73.80-83.05 \rrbracket$ & 19 & 78.89ه71.61-86.18ه & 21 & 78.00ه71.53-84.47ه & 0.807 \\
\hline Memory-related diseases & 49 & $78.71 \otimes 74.51-82.92 \rrbracket$ & 20 & $78.80 \otimes 72.10-85.50 \otimes$ & 29 & $78.66 \rrbracket 72.92-84.40 \rrbracket$ & 0.894 \\
\hline Arthritis & 303 & $78.01 \otimes 76.36-79.65 \rrbracket$ & 121 & $77.00 \otimes 74.24-79.76 \rrbracket$ & 182 & $78.68 \rrbracket 76.62-80.73 \rrbracket$ & 0.471 \\
\hline
\end{tabular}

** $P<0.001 ; * P<0.05 ; \mathrm{Cl}$ indicates confidence interval; EQ-5D-5L, Euroqol-five dimensions-five levels; EQ-VAS, European quality of life-Visual Analogue Scale; COPD, chronic obstructive pulmonary disease; CHD, coronary heart disease;

Table 3. EQ-5D-5L norm utility scores according to sex. 


\begin{tabular}{|c|c|c|c|c|c|}
\hline \multirow[t]{2}{*}{ Variables } & \multicolumn{2}{|l|}{ Men } & \multicolumn{2}{|c|}{ Women } & \multirow[t]{2}{*}{$P$ value } \\
\hline & $\mathrm{n}$ & mean $(95 \% \mathrm{Cl})$ & $\mathrm{n}$ & mean $(95 \% \mathrm{Cl})$ & \\
\hline \multicolumn{6}{|l|}{ Age groups $\llbracket$ year $\rrbracket$} \\
\hline $18-30$ & 689 & $0.994(0.990-0.998)$ & 718 & 0.999(0.998-1.000) & 0.056 \\
\hline $31-40$ & 769 & 0.996(0.994-0.997) & 930 & 0.994(0.991-0.997) & 0.340 \\
\hline $41-50$ & 1117 & $0.990(0.987-0.994)$ & 1291 & $0.988(0.986-0.991)$ & $0.008^{*}$ \\
\hline $51-60$ & 928 & $0.984(0.980-0.988)$ & 977 & $0.982(0.979-0.986)$ & 0.177 \\
\hline $61-70$ & 656 & $0.976(0.971-0.980)$ & 755 & $0.964(0.958-0.971)$ & $0.011^{*}$ \\
\hline $70+$ & 575 & $0.947(0.936-0.958)$ & 651 & $0.936(0.926-0.946)$ & $0.015^{\star}$ \\
\hline \multicolumn{6}{|l|}{ Education level } \\
\hline Primary schools or below & 1189 & $0.966(0.960-0.971)$ & 1895 & $0.960(0.955-0.964)$ & 0.063 \\
\hline Junior middle school & 1862 & $0.985(0.982-0.988)$ & 1935 & $0.987(0.985-0.990)$ & 0.805 \\
\hline High school or similar & 1064 & $0.991(0.988-0.995)$ & 840 & $0.995(0.992-0.997)$ & 0.171 \\
\hline Junior college and above & 619 & 0.997(0.996-0.998) & 649 & 0.998(0.997-0.999) & 0.849 \\
\hline \multicolumn{6}{|c|}{ Annual household income区yuan, RMB囚 } \\
\hline$<50000$ & 1228 & $0.962(0.956-0.969)$ & 1460 & $0.957(0.951-0.962)$ & $0.011^{*}$ \\
\hline $50000-99999$ & 1521 & $0.986(0.984-0.989)$ & 1795 & $0.985(0.982-0.988)$ & 0.170 \\
\hline 100000-149999 & 1076 & $0.993(0.991-0.995)$ & 1155 & $0.991(0.989-0.993)$ & 0.092 \\
\hline$\geq 150000$ & 909 & $0.994(0.992-0.996)$ & 912 & $0.992(0.990-0.994)$ & 0.262 \\
\hline \multicolumn{6}{|l|}{$\mathrm{BMI} \varangle \mathrm{kg} / \mathrm{m}^{2} \square$} \\
\hline$<18.5 / 18.5-23.9$ & 2481 & $0.984(0.982-0.987)$ & 3160 & $0.983(0.980-0.985)$ & 0.774 \\
\hline $24.0-27.9$ & 1782 & $0.982(0.978-0.985)$ & 1658 & $0.978(0.975-0.981)$ & $<0.001^{* *}$ \\
\hline$\geq 28.0$ & 471 & $0.983(0.976-0.989)$ & 504 & $0.968(0.959-0.976)$ & $<0.001^{* *}$ \\
\hline
\end{tabular}

** $P<0.001 ; * P<0.05 ; \mathrm{Cl}$, confidence interval; BMI, Body mass index.

Table 4. EQ-5D-5L utility score and EQ-VAS score by different domains of EQ-5D-5L scale. 


\begin{tabular}{|c|c|c|c|c|}
\hline \multirow[t]{2}{*}{ Domains } & \multicolumn{2}{|l|}{ EQ- VAS scores } & \multicolumn{2}{|c|}{ EQ-5D-5L Utility scores } \\
\hline & Mean $\nabla 95 \% \mathrm{Cl} \nabla$ & $P$ value & Mean $₫ 95 \% \mathrm{Cl} \rrbracket$ & $P$ value \\
\hline \multicolumn{5}{|l|}{ MO } \\
\hline No problems & 83.94『83.58-84.29囚 & \multirow[t]{2}{*}{$<0.001^{* \star}$} & $0.989 ه 0.988-0.990 \rrbracket$ & \multirow[t]{2}{*}{$<0.001^{\star *}$} \\
\hline problems & 67.94『64.83-71.05囚 & & $0.662 \rrbracket 0.630-0.694 \rrbracket$ & \\
\hline \multicolumn{5}{|l|}{ SC } \\
\hline No problems & 83.85囚83.49-84.20囚 & \multirow[t]{2}{*}{$<0.001^{* *}$} & $0.987 \rrbracket 0.986-0.988 \rrbracket$ & \multirow[t]{2}{*}{$<0.001^{\star *}$} \\
\hline problems & 64.41ه59.97-68.86ه & & $0.589 ه 0.541-0.637 \rrbracket$ & \\
\hline \multicolumn{5}{|l|}{ UA } \\
\hline No problems & 83.94『83.59-84.30囚 & \multirow[t]{2}{*}{$<0.001^{\star \star *}$} & 0.989ه0.988-0.990ه & \multirow[t]{2}{*}{$<0.001^{\star *}$} \\
\hline problems & $67.74 \llbracket 64.50-70.97 \rrbracket$ & & $0.677 \rrbracket 0.644-0.709 \rrbracket$ & \\
\hline \multicolumn{5}{|l|}{ PD } \\
\hline No problems & $84.37 \llbracket 84.00-84.75 \rrbracket$ & \multirow[t]{2}{*}{$<0.001^{* *}$} & 0.997ه0.996-0.998囚 & \multirow[t]{2}{*}{$<0.001^{\star *}$} \\
\hline problems & 77.38囚76.25-78.50冈 & & $0.864 \rrbracket 0.855-0.873 \rrbracket$ & \\
\hline \multicolumn{5}{|l|}{$A D$} \\
\hline No problems & 83.83₫83.46-84.19® & \multirow[t]{2}{*}{$<0.001^{\star \star}$} & 0.990ه0.989-0.990ه & \multirow[t]{2}{*}{$<0.001^{\star \star}$} \\
\hline problems & 79.09ه77.27-80.91囚 & & $0.816 \rrbracket 0.799-0.834 \rrbracket$ & \\
\hline \multicolumn{5}{|l|}{ All domains } \\
\hline Problem-free & $84.48 \rrbracket 84.10-84.85 \rrbracket$ & \multirow[t]{2}{*}{$<0.001^{\star *}$} & 1.000 & \multirow[t]{2}{*}{$<0.001^{\star *}$} \\
\hline At least a problem & 78.07ه77.06-79.09囚 & & $0.871 \rrbracket 0.863-0.878 \rrbracket$ & \\
\hline
\end{tabular}

** $P<0.001$; * $P<0.05$; EQ-5D-5L, Euroqol-five dimensions-five levels; EQ-VAS, European quality of life-Visual Analogue Scale; Cl, confidence interval; MO, mobility; SC, self-care; UA, usual activities; PD, pain or discomfort; AD, anxiety or depression.

Table 5. The incidence of self-reported health problems using the EQ-5D-5L descriptive system by age group and sex (\%). 


\begin{tabular}{|c|c|c|c|c|c|c|c|c|c|c|c|c|c|}
\hline Level & MO & & & SC & & & UA & & & PD & & & $A D$ \\
\hline & Total & Men & Women & Total & Men & Women & Total & Men & Women & Total & Men & Women & Total \\
\hline \multicolumn{14}{|l|}{ All } \\
\hline $\begin{array}{l}\text { No } \\
\text { problems }\end{array}$ & 97.67 & 97.68 & 97.67 & 98.66 & 98.63 & 98.68 & 97.61 & 97.74 & 97.50 & 88.04 & 89.37 & 86.87 & 95.32 \\
\hline Problems & 2.33 & 2.32 & 2.33 & 1.34 & 1.37 & 1.32 & 2.39 & 2.26 & 2.50 & 11.96 & 10.63 & 13.13 & 4.68 \\
\hline \multicolumn{14}{|l|}{$\begin{array}{l}18-30 \\
\text { years }\end{array}$} \\
\hline $\begin{array}{l}\text { No } \\
\text { problems }\end{array}$ & 99.79 & 99.56 & 100.00 & 99.72 & 99.42 & 100.00 & 99.50 & 98.98 & 100.00 & 98.36 & 97.67 & 99.03 & 98.29 \\
\hline Problems & 0.21 & 0.44 & 0.00 & 0.28 & 0.58 & 0.00 & 0.50 & 1.02 & 0.00 & 1.64 & 2.33 & 0.97 & 1.71 \\
\hline \multicolumn{14}{|l|}{$\begin{array}{l}31-40 \\
\text { years }\end{array}$} \\
\hline $\begin{array}{l}\text { No } \\
\text { problems }\end{array}$ & 99.71 & 99.74 & 99.68 & 99.76 & 99.87 & 99.68 & 99.53 & 99.61 & 99.46 & 97.23 & 97.14 & 97.31 & 96.76 \\
\hline Problems & 0.29 & 0.26 & 0.32 & 0.24 & 0.13 & 0.32 & 0.47 & 0.39 & 0.54 & 2.77 & 2.86 & 2.69 & 3.24 \\
\hline \multicolumn{14}{|l|}{$\begin{array}{l}41-50 \\
\text { years }\end{array}$} \\
\hline $\begin{array}{l}\text { No } \\
\text { problems }\end{array}$ & 99.13 & 98.84 & 99.38 & 99.42 & 99.37 & 99.46 & 99.04 & 98.93 & 99.15 & 93.11 & 94.18 & 92.18 & 95.93 \\
\hline Problems & 0.87 & 1.16 & 0.62 & 0.58 & 0.63 & 0.54 & 0.96 & 1.07 & 0.85 & 6.89 & 5.82 & 7.82 & 4.07 \\
\hline \multicolumn{14}{|l|}{$\begin{array}{l}51-60 \\
\text { years }\end{array}$} \\
\hline $\begin{array}{l}\text { No } \\
\text { problems }\end{array}$ & 99.00 & 98.81 & 99.18 & 99.48 & 99.35 & 99.59 & 98.90 & 98.60 & 99.18 & 86.61 & 88.36 & 84.95 & 95.49 \\
\hline Problems & 1.00 & 1.19 & 0.82 & 0.52 & 0.65 & 0.41 & 1.10 & 1.40 & 0.82 & 13.39 & 11.64 & 15.05 & 4.51 \\
\hline \multicolumn{14}{|l|}{$\begin{array}{l}61-70 \\
\text { years }\end{array}$} \\
\hline $\begin{array}{l}\text { No } \\
\text { problems }\end{array}$ & 96.60 & 96.95 & 96.29 & 98.87 & 98.93 & 98.91 & 96.60 & 97.41 & 95.89 & 76.75 & 79.73 & 74.17 & 93.76 \\
\hline Problems & 3.40 & 3.05 & 3.71 & 1.13 & 1.07 & 1.19 & 3.40 & 2.59 & 4.11 & 23.25 & 20.27 & 25.83 & 6.24 \\
\hline \multicolumn{14}{|l|}{$\begin{array}{l}>70 \\
\text { years }\end{array}$} \\
\hline $\begin{array}{l}\text { No } \\
\text { problems }\end{array}$ & 88.74 & 89.39 & 88.17 & 92.90 & 93.04 & 92.78 & 89.15 & 90.43 & 88.02 & 68.76 & 72.35 & 65.59 & 90.21 \\
\hline Problems & 11.26 & 10.61 & 11.83 & 7.10 & 6.96 & 7.22 & 10.85 & 9.57 & 11.98 & 31.24 & 27.65 & 34.41 & 9.79 \\
\hline$x^{2}$ & 532.89 & 212.46 & 324.37 & 354.58 & 152.92 & 203.69 & 465.89 & 166.33 & 307.02 & 944.75 & 366.51 & 581.92 & 117.15 \\
\hline$P^{k \star}$ & $\begin{array}{l}<0.001 P<0.001 \\
* P<0.05\end{array}$ & $<0.001$ & $<0.001$ & $<0.001$ & $<0.001$ & $<0.001$ & $<0.001$ & $<0.001$ & $<0.001$ & $<0.001$ & $<0.001$ & $<0.001$ & $<0.001$ \\
\hline
\end{tabular}

** All $P<0.01$; Values are presented as percentages; MO, mobility; SC, self-care; UA, usual activities; PD, pain or discomfort; AD, anxiety or depression.

Table 6. Tobit regression analyses and Generalized linear model on the EQ-5D-5L utility scores and EQ-VAS scores. 


\begin{tabular}{|c|c|c|c|c|c|c|}
\hline \multirow[t]{2}{*}{ Variables } & \multicolumn{3}{|c|}{ EQ-5D-5L utility scores } & \multicolumn{3}{|c|}{ EQ-VAS scores } \\
\hline & Coef. & $S E$ & $P$ & Coef. & $S E$ & $P$ \\
\hline \multicolumn{7}{|l|}{ Sex } \\
\hline \multicolumn{7}{|l|}{ Male $₫ \operatorname{Ref} \rrbracket$} \\
\hline Female & -0.006 & 0.011 & 0.585 & -0.019 & 0.004 & $<0.001^{\star *}$ \\
\hline \multicolumn{7}{|l|}{ Age group \year $\rrbracket$} \\
\hline \multicolumn{7}{|l|}{ 18-30囚Ref囚 } \\
\hline $31-40$ & -0.054 & 0.022 & $0.015^{\star}$ & -0.037 & 0.007 & $<0.001^{\star *}$ \\
\hline $41-50$ & -0.105 & 0.022 & $<0.001^{\star \star}$ & -0.055 & 0.007 & $<0.001^{\star \star}$ \\
\hline $51-60$ & -0.137 & 0.022 & $<0.001^{\star \star}$ & -0.067 & 0.007 & $<0.001^{\star \star}$ \\
\hline $61-70$ & -0.156 & 0.024 & $<0.001$ ** & -0.079 & 0.008 & $<0.001^{\star *}$ \\
\hline $70+$ & -0.195 & 0.024 & $<0.001^{\star *}$ & -0.101 & 0.008 & $<0.001^{* *}$ \\
\hline \multicolumn{7}{|l|}{ Residence } \\
\hline \multicolumn{7}{|l|}{ Urban囚Ref囚 } \\
\hline Rural & -0.078 & 0.015 & $<0.001^{\star \star}$ & -0.053 & 0.005 & $<0.001^{\star \star}$ \\
\hline \multicolumn{7}{|l|}{ Education level } \\
\hline \multicolumn{7}{|c|}{ Primary schools and below $₫ \operatorname{Ref} \rrbracket$} \\
\hline Junior middle school & 0.044 & 0.010 & $<0.001 * *$ & 0.025 & 0.005 & $<0.001^{* *}$ \\
\hline High school or similar & 0.078 & 0.015 & $<0.001$ ** & 0.018 & 0.006 & $0.003^{*}$ \\
\hline Junior College and above & 0.119 & 0.023 & $<0.001^{\star \star}$ & 0.025 & 0.007 & $<0.001^{\star *}$ \\
\hline \multicolumn{7}{|c|}{ Annual household income $\ y u a n, R M B \bigotimes$} \\
\hline \multicolumn{7}{|l|}{$<50000 \otimes R e f 囚$} \\
\hline $50000-99999$ & 0.041 & 0.010 & $<0.001$ ** & 0.027 & 0.005 & $<0.001^{\star *}$ \\
\hline 100000-149999 & 0.062 & 0.013 & $<0.001^{\star *}$ & 0.029 & 0.005 & $<0.001^{\star *}$ \\
\hline$\geq 150000$ & 0.059 & 0.014 & $<0.001^{\star *}$ & 0.048 & 0.006 & $<0.001^{* *}$ \\
\hline \multicolumn{7}{|l|}{ Employment status } \\
\hline \multicolumn{7}{|c|}{ Retired/homemaker/unemployed/student $囚 \operatorname{Ref} \rrbracket$} \\
\hline Paid employment & 0.070 & 0.009 & $<0.001$ ** & 0.010 & 0.004 & $0.017 *$ \\
\hline \multicolumn{7}{|l|}{ Marital status } \\
\hline \multicolumn{7}{|l|}{ Married $\otimes \operatorname{Ref} \rrbracket$} \\
\hline Unmarried/divorce/widow & -0.040 & 0.012 & $0.001^{* \star}$ & -0.042 & 0.005 & $<0.001^{\star *}$ \\
\hline \multicolumn{7}{|l|}{ Regular physical activities } \\
\hline \multicolumn{7}{|l|}{ No囚Ref囚 } \\
\hline Yes & 0.028 & 0.008 & $0.001^{\star *}$ & -0.005 & 0.003 & 0.131 \\
\hline \multicolumn{7}{|l|}{ Smoking status } \\
\hline \multicolumn{7}{|l|}{ Smoking status } \\
\hline \multicolumn{7}{|l|}{ Never囚Ref $\bigotimes$} \\
\hline Current & 0.003 & 0.013 & 0.837 & -0.003 & 0.005 & 0.532 \\
\hline Former & -0.065 & 0.021 & $0.001^{*}$ & -0.033 & 0.010 & $<0.001^{\star *}$ \\
\hline \multicolumn{7}{|l|}{ Drinking status } \\
\hline \multicolumn{7}{|l|}{ Never $\rrbracket \operatorname{Ref} \rrbracket$} \\
\hline Current & -0.005 & 0.011 & 0.637 & -0.026 & 0.005 & $<0.001^{\star \star}$ \\
\hline
\end{tabular}

Page 14/15 


\begin{tabular}{|c|c|c|c|c|c|c|}
\hline \multicolumn{7}{|l|}{$\leq 23.9 \otimes R e f \rrbracket$} \\
\hline 24.0 to 27.9 & -0.008 & 0.009 & 0.340 & -0.006 & 0.003 & 0.106 \\
\hline$\geq 28.0$ & -0.014 & 0.013 & 0.283 & -0.007 & 0.006 & 0.183 \\
\hline \multicolumn{7}{|c|}{ The number of NCDs } \\
\hline \multicolumn{7}{|l|}{ O凶Ref囚 } \\
\hline 1 & -0.037 & 0.010 & $<0.001 * \star$ & -0.010 & 0.005 & $0.027 *$ \\
\hline$\geq 2$ & -0.141 & 0.013 & $<0.001 * *$ & -0.041 & 0.007 & $<0.001^{\star *}$ \\
\hline
\end{tabular}

** $P<0.001 ; * P<0.05$; EQ-5D-5L, Euroqol-five dimensions-five levels; EQ-VAS, European quality of life-Visual Analogue Scale; Ref, the reference group; Coef, coefficient; SE, Standard error; BMI, Body mass index; NCDs, chronic non-communicable diseases; Paid employment, whether employed, full-time or part-time; 